\title{
Nursing and Allied Health Staff Perceptions and Experiences of a Volunteer Stroke Peer Support Program: A Qualitative Study
}

\author{
Rosemary Saunders (1D \\ Kien Chan (iD) ${ }^{2}$ \\ Renée M Graham (D) \\ Elena Adams (iD) ${ }^{2}$ \\ Caroline E Bulsara $\mathbb{D D}^{3}$ \\ Karla Seaman (D) \\ Marcella Cranny-Connolly $\mathbb{D D}^{2}$ \\ 'Centre for Research in Aged Care, \\ School of Nursing \& Midwifery, Edith \\ Cowan University, Joondalup, Western \\ Australia, Australia; ${ }^{2}$ Stroke Services, \\ Osborne Park Hospital, Osborne Park, \\ Western Australia, Australia; ${ }^{3}$ School of \\ Nursing Midwifery \& Institute for Health \\ Research, The University of Notre Dame \\ Australia, Fremantle, Western Australia, \\ Australia
}

\begin{abstract}
Purpose: Stroke brings about physical, cognitive, and psychosocial changes and, consequently, many stroke survivors feel underprepared for the transition from hospital to home. Nursing and allied health staff have a key role in stroke rehabilitation. Peer support programs have been found effective in supporting stroke survivors, alongside hospital staff caring for stroke patients, by providing experiential knowledge that staff are not able to provide.
\end{abstract}

Aim: This study explored the perceptions and experiences of nursing and allied health staff of a volunteer peer support program for stroke inpatients.

Methods: This study utilised a qualitative, evaluative case study design. This study was conducted at a public metropolitan hospital in Western Australia that had developed a stroke peer support program (SPSP) on a rehabilitation ward. A purposeful sample of nurses $(n=5)$ and multidisciplinary allied health $\operatorname{staff}(\mathrm{n}=5)$ were recruited from the ward where the SPSP was provided for stroke inpatients. Semi-structured, face-to-face interviews were conducted with staff participants. Verbatim transcripts from audio-recorded interviews were analysed using inductive thematic analysis.

Results: Nursing and allied health staff perceived the SPSP as valuable to stroke patients' rehabilitation and beneficial to families, volunteer peers and staff. Four themes encapsulated the findings: awareness of and involvement in the program; recognising the benefits of the program; perceived enablers and barriers of the program and suggestions for the future of the program.

Conclusion: Nursing and allied health staff within multidisciplinary teams are cognisant of the psycho-emotional needs of stroke patients which staff are not fully able to meet. The study findings confirm volunteer peer support can provide valuable and fundamental adjunct support to address stroke patients' unmet needs, as well as supporting staff to enhance stroke patient care. Keywords: stroke, stroke rehabilitation, stroke recovery, peer support, program evaluation, nursing

\section{Plain Language Summary}

Stroke survivors often feel unsure about how the effects of their stroke will impact them and how they will cope when they are discharged from hospital. Stroke peer support programs involve former stroke survivors and their family carers who visit patients in hospital who have recently had a stroke, and their families. Peer support stroke survivors work alongside doctors, nurses, and allied health staff (physiotherapists, speech therapists, occupational therapists, and dietitians) to prepare inpatients for discharge. These programs are reported to be helpful to inpatient stroke survivors and their families, but little is known about the staff experiences of these programs.
Correspondence: Rosemary Saunders Centre for Research in Aged Care, School of Nursing \& Midwifery, Edith Cowan University, 270 Joondalup Drive, Joondalup, Western Australia, 6027, Australia

Tel +6I 863043513

Email rosemary.saunders@ecu.edu.au 
The aim of this study was to explore nurses and other and allied health staff experiences of a volunteer peer support program for stroke inpatients in a rehabilitation ward at a community hospital in Perth, Western Australia. This study was undertaken by interviewing ten staff members and asking them questions about the role of the peer volunteers, the benefits of the program, and suggestions for the future of the program.

The research found staff highly valued the stroke peer support program, as through stroke survivor volunteers sharing their stories, it provided inpatients with hope and encouragement, whilst also providing adjunct support that staff could not provide. Staff also observed benefits for the volunteer peer supporters. Volunteer peer support was regarded as an important part of stroke patient rehabilitation, and all participants agreed the program should continue.

Based on these study findings, it is recommended that stroke rehabilitation units implement stroke peer support programs. These findings have been communicated in conference presentations and in a report to the study hospital and have contributed to the continuation of the program.

\section{Introduction}

Stroke is a leading cause of mortality and disability worldwide, with over 13 million new strokes occurring worldwide in 2016. ${ }^{1}$ There are over 80 million people currently living who have experienced a stroke globally and of these $60 \%$ are aged under 70 years. ${ }^{2}$ The multitude of physical, cognitive, and psycho-emotional consequences experienced by stroke survivors presents a challenge for healthcare professionals involved in their acute and rehabilitative care.

The suddenness and immense impacts of stroke can potentially bring about feelings of distress, uncertainty, fear and loneliness in the stroke survivor ${ }^{3-5}$ and research indicates stroke patients need better access to psychosocial support from the acute care stage, including information, advice, and social support to facilitate the requisite psychological adjustments following a stroke episode. ${ }^{6}$ Furthermore, social and cognitive deficits observed during the acute phase following stroke have been associated with poorer functional outcomes at 6 months post-stroke. ${ }^{3}$

The provision of timely, comprehensive clinical care and rehabilitation by specialist multidisciplinary stroke teams is a key component of stroke treatment and management. Clinical guidelines for stroke management define rehabilitation as "a holistic process that should begin the first day after stroke with the aim of maximising the participation of the person with stroke in the community"7 and "a multidimensional process, which is designed to facilitate restoration of, or adaptation to the loss of, physiological or psychological function when reversal of the underlying pathological process is incomplete". Therefore, the overall aim of stroke rehabilitation is to improve quality of life through maximising patients' physical, psychological, and social functioning and independence. $^{9}$

Healthcare professionals have shared the challenges of providing adequate support to wholly address stroke patients' considerable psychological needs in hospital and immediately post-discharge. ${ }^{6}$ Similarly, patients have indicated the need for more information about stroke recovery to aid their adjustment to stroke. ${ }^{10}$ Neurocritical care nurses suggest the primary drivers of distress among stroke survivors are a lack of resiliency skills, compromised problem solving, negative thinking styles, lack of interpersonal communication and little or no family support. These are all factors considered detrimental to recovery, thereby highlighting the importance of fostering selfcare in patients in preparation for the transition from hospital to home. ${ }^{4}$ However, rehabilitation teams are often challenged by healthcare organisation demands, complexities of patient needs and limited resourcing and time, thus, volunteers are emerging as valuable contributors to the support of patients in stroke rehabilitation. ${ }^{6,11,12}$

Studies suggest that healthcare professionals have recognised the value of peer support volunteers as part of stroke rehabilitation to specifically address the psychosocial and information support needs of recent stroke survivors, as former stroke survivors and their carers are able to share their experiences and provide relatable social support that other volunteers and healthcare professionals are not able to provide. ${ }^{12,13}$ Stroke organisations have actively encouraged peer support programs and one such program was developed in Australia, where aa peer support informational program was piloted across six stroke and rehabilitation wards in five metropolitan hospital sites in Melbourne, Australia. ${ }^{10}$ The program was co-facilitated by a National Stroke Foundation health professional and a peer role model who provided one-hour in-hospital information sessions for stroke survivors on transitioning from hospital to home. ${ }^{10}$ Nurses reported some barriers to the successful implementation of the program, namely, poor engagement of some healthcare professionals, the necessary prioritisation of routine ward activities, and limited patient access to the program due to scheduling conflicts with admissions and discharges. Despite these challenges, nurses reported that championing the program 
was not a burden to them and felt the program was of value to patients. Nurses received positive feedback from patients and wanted to see the program continue with adjustments to the timing of the program. ${ }^{10}$

A study of a Canadian-based peer support program explored stroke survivors, care partners, volunteer peers, program coordinators and healthcare professionals' perceptions and experiences of the program. ${ }^{11}$ The one-on-one program comprised an initial ten minute in-hospital visit from a peer, followed by post-discharge telephone support with the stroke survivor or carer, at one, three, six, nine and twelve months. Participants perceived that peer support offered patients emotional and informational support while increasing motivation and reducing loneliness. ${ }^{11}$

Thus, understanding nursing and allied health staff perceptions and experiences of providing volunteer stroke peer support programs is valuable as they have insights into stroke patients' and carers' emotional distress and unmet needs which can inform the design or refinement of peer support programs. In this study, the perceptions of nursing and allied health staff of the SPSP at metropolitan public hospital were explored, as part of a broader evaluation of the SPSP.

\section{Materials and Methods}

A qualitative, evaluative case study design was used. The Consolidation criteria for reporting qualitative research (COREQ) guidelines were adhered to for this study.

\section{Setting and Participants}

The study was conducted with nursing and allied health staff working in a 10-bed stroke unit within a metropolitan public hospital in Western Australia. The stroke unit is part of a 30-bed rehabilitation ward that admits up to 160 stroke patients annually, with an average length of stay of 3.5 weeks per patient. The hospital introduced a Stroke Peer Support Program (SPSP) in 2017, modelled on the National Stroke Foundation's Hospital Peer Support Program (HPSP). ${ }^{10}$ The program provides individual peer support for up to one hour per week by trained volunteer peers (former stroke survivors or carers of former stroke survivors of the hospital). Inpatient stroke survivors are invited to be in the SPSP according to selection criteria (Figure 1).

Volunteers are recruited from the pool of former stroke survivor patients. There are no specific criteria and no required timeframe post-discharge for interested discharged stroke survivors to volunteer. During the training the ability to communicate with patients is informally assessed. Volunteer peers complete a comprehensive 2 day training program, (day one includes content related to volunteers' scope of practice, communication skills, and strategies for dealing with challenging scenarios, plus a hospital orientation; and day 2 comprises practical application of theory through role play activities).

The SPSP is led by a clinical nurse (who manages the scheduling of visits) and volunteer coordinator (who manages the recruitment and rostering of volunteers) in partnership with the rehabilitation team. During weekly staff meetings, the MDT discusses and generates a list of stroke inpatients who they think may benefit from receiving peer support. These inpatients are informed of the SPSP and invited to receive a visit from a volunteer. If the inpatient wishes to participate, the MDT matches the patient with the most suitable peer volunteer. If the inpatient chooses

Inclusion criteria (one or more of must be present):

1. Patient needs support/motivation/advice

2. Patient has very little family/friends visiting

3. Patient is socially isolated

4. Patient rehabilitation goals fit with this program

5. Patient carer requires support/advice.

Exclusion criteria (one or more of must be present):

1. Patient is severely aphasic, and communication is very difficult

2. Patient is at high risk of suicide/self-harm and requires professional support

3. Patient cognition is severely affected, and interaction would be too difficult for a volunteer peer

4. Patient is at high risk of infection and/or there are infection control issues present.

Figure I Patient selection criteria for the stroke peer support program. 
not to participate, usual medical care continues, and if deemed appropriate by the MDT, the invite is extended again in a subsequent week. The assigned volunteer peer visits with the stroke inpatient for one hour per week during their hospital stay, discussing their personal experiences of having a stroke, undergoing recovery and rehabilitation, adjusting to life after hospital, and other spontaneously occurring topics.

\section{Data Collection}

Purposive sampling was used to recruit nursing and allied health staff who had worked on the rehabilitation ward for three months or longer. Information about the study was communicated at the staff ward meeting, the multidisciplinary team meeting, and via email. Ten participants attended a semi-structured, face-to-face interview with a researcher during October and November 2019 in a private meeting room at the hospital site. The researcher conducting the interviews had no prior relationship to the participants. Participant information sheets were provided, and written consent obtained (including a statement informing participants that study findings will be published through health journals or professional meetings, and that participants would not be identified in these communications). Participants responded to seven open-ended interview questions. The question guide focused on staff experiences of the SPSP, the perceived benefits and positive impacts, barriers and challenges, and areas for improvement. Due to the limited availability of staff, four interviews were conducted individually (one interviewer to one staff participant) while three interviews were conducted in pairs (one interviewer to two staff participants), and data saturation was achieved through these interviews.

\section{Data Analysis}

All interviews were audio recorded verbatim and transcribed for analysis. Transcriptions were imported into NVivo (Version 12) and analysed using an inductive thematic analysis approach guided by the six-step approach of Braun and Clarke. ${ }^{14}$ Strategies to ensure rigour were achieved and ensured trustworthiness. ${ }^{15}$ Two independent researchers carried out coding of the transcribed interviews, contributing to the credibility. To ensure transferability, a detailed description of the research setting, environment, nurse and allied health participants and results are provided. Dependability was gained by following a comprehensive data collection procedure. Confirmability was conducted by the research team through an iterative process of developing and refining emerging themes and repeated reviewing of transcriptions.

\section{Ethical Approval}

The study was approved by Sir Charles Gairdner and Osborne Park Health Care Group Human Research Ethics Committee (RGS0000001000) and Edith Cowan University Human Research Ethics Committee (21018 SAUNDERS).

\section{Results}

Ten nursing and allied health staff participated in semistructured interviews over a two-month period $(n=5$ nurses; $n=5$ allied health staff). Nursing and allied health staff had worked at the hospital site between two and 15 years, and all had worked on the rehabilitation ward for greater than three months.

Nursing and allied health staff overwhelmingly valued the SPSP and the contributions of both volunteer peers and staff who performed the day-to-day running of the program. Four overarching themes and related sub-themes described nursing and allied health staff experiences of the program (Figure 2). Representative quotations from the interviews are outlined in Table 1.

\section{Awareness of and Involvement in the Program}

The SPSP was known to all nursing and allied health staff and was clearly identified as being part of the stroke rehabilitation ward, though staff had varied levels of direct involvement. Volunteers interacted regularly with the coordinating clinical nurse and interacted with nursing and allied health ward staff on an ad hoc basis as they were

\begin{tabular}{|c|c|}
\hline $\begin{array}{l}\text { Awareness of and } \\
\text { involvement in the } \\
\text { program }\end{array}$ & $\begin{array}{l}\text { - Levels of involvement } \\
\text { - Referral of patients and volunteer peers }\end{array}$ \\
\hline $\begin{array}{l}\text { Recognising the } \\
\text { benefits of the } \\
\text { program }\end{array}$ & $\begin{array}{l}\text { - Benefits to patients and family } \\
\text { - Benefits to volunteer peers } \\
\text { - Benefits to staff }\end{array}$ \\
\hline $\begin{array}{c}\text { Perceived enablers } \\
\text { and barriers of the } \\
\text { program }\end{array}$ & $\begin{array}{l}\text { - Enablers of the sucess of the program } \\
\text { - Barriers to the success of the program }\end{array}$ \\
\hline $\begin{array}{l}\text { Suggestions for the } \\
\text { future of the } \\
\text { program }\end{array}$ & - Program development and expansion \\
\hline
\end{tabular}

Figure 2 Summary of themes and subthemes. 
Table I Themes and Representative Quotations

\begin{tabular}{|c|c|c|}
\hline Theme & Subtheme & Representative Quotation \\
\hline \multirow[t]{2}{*}{$\begin{array}{l}\text { Awareness of and } \\
\text { involvement in the program }\end{array}$} & Levels of involvement & $\begin{array}{l}\text { "Respectfully, every volunteer comes to the ward clerk's station, they let us know that } \\
\text { they're there, and then they proceed to go around to the patients. Always friendly, the } \\
\text { patients look forward to it." [Participant } 10 \text { - Nurse] }\end{array}$ \\
\hline & $\begin{array}{l}\text { Referral of patients and } \\
\text { volunteer peers }\end{array}$ & $\begin{array}{l}\text { "... and there is weekly meetings, we also recommend all the people that may be } \\
\text { appropriate to be part of it, as in the clients, the patients themselves that are on the } \\
\text { ward at the time. So we will say 'yes such and such' and they will be put down for the } \\
\text { nurse to then contact, whether they'd like to see [a volunteer] that week or not." } \\
\text { [Participant } 2 \text { - Allied Health Staff] }\end{array}$ \\
\hline \multirow[t]{3}{*}{$\begin{array}{l}\text { Recognising the benefits of } \\
\text { the program }\end{array}$} & $\begin{array}{l}\text { Benefits to patients and } \\
\text { family }\end{array}$ & $\begin{array}{l}\text { "I think the benefits are huge ... I think it's really important for the patients to meet } \\
\text { someone that's been through what they have been through ... ... for them to see } \\
\text { someone on the other side and know that their life is not always going to be always } \\
\text { sitting in the hospital bed." [Participant } 5 \text { - Allied Health Staff] } \\
\text { "Any interaction they have with anyone is good, because it can, it's quite isolating, it's } \\
\text { life changing having a stroke and their whole world is, you know, turned upside down. } \\
\text { So having anyone else from the outside is beneficial to a patient ..." [Participant I0- } \\
\text { Nurse] } \\
\text { "So benefits to the patients is they can see a light at the end of the tunnel, because } \\
\text { patients do not understand they are in the process of getting better, but they do not } \\
\text { see the progress that they do make and it's nice to have someone that's been through } \\
\text { the process .... [Participant } 3 \text { - Nurse] } \\
\text { "I think the carer goes through a lot of grief and really, you know, because they have } \\
\text { lost what their partner was, and I think you know, that they can talk to somebody that } \\
\text { has been through that and that I think it's hard for the carer sometimes to talk to the } \\
\text { person that's had the stroke." [Participant } 7 \text { - Allied Health Staff] }\end{array}$ \\
\hline & $\begin{array}{l}\text { 4.2.2 Benefits to } \\
\text { volunteer peers }\end{array}$ & $\begin{array}{l}\text { "I think there's also a huge benefit to the volunteer peers that should not be } \\
\text { overlooked. I think that they have a big purpose, it's keeping them active, it's getting } \\
\text { them out of the house, they are kind of accountable to someone, and I think that } \\
\text { there's probably a huge benefit to volunteer peers as well as the patients." [Participant } \\
5 \text { - Allied Health Staff] }\end{array}$ \\
\hline & 4.2.3 Benefits to staff & $\begin{array}{l}\ldots \text {.. [it] almost takes a little bit of pressure off of us, if we know that the volunteer is } \\
\text { doing some of that, and they have got an hour that they are going to be spending with } \\
\text { someone else. So that would be [the main] benefit for staff ..." [Participant } 5 \text { - Allied } \\
\text { Health Staff] } \\
\text { "... sometimes your work's really hard and it's really sad and [that] whole compassion } \\
\text { fatigue starts coming in and then, you know, one of the volunteer peers might walk } \\
\text { onto the ward and it just reminds you that some of our stroke survivors do get home } \\
\text { and do get back to the community and do get to start living their life again, and so it } \\
\text { kind of peps you up to keep you going and ..." [Participant } 8 \text { - Allied Health Staff] }\end{array}$ \\
\hline \multirow[t]{2}{*}{$\begin{array}{l}\text { 4.3 Perceived enablers and } \\
\text { barriers of the program }\end{array}$} & $\begin{array}{l}\text { 4.3.I Enablers of the } \\
\text { success of the program }\end{array}$ & $\begin{array}{l}\text { "We do not do the day-to-day running and [phone] calling, organising it. We have got } \\
\text { to have someone that can do that, so I think that that's really important, having, [the } \\
\text { volunteer coordinator] ... ... none of us have the time to do all that calling and } \\
\text { emailing and everything else that happens. So I think having that person is the biggest } \\
\text { enabler." [Participant } 5 \text { - Allied Health Staff] }\end{array}$ \\
\hline & $\begin{array}{l}\text { 4.3.2 Barriers to the } \\
\text { success of the program }\end{array}$ & $\begin{array}{l}\text { "... I think the only barrier might be the timing. Like the bad timing is the afternoon. } \\
\text { It depends really the days, like weekends we would have so much more time, during } \\
\text { the weekdays there is so much going on, different physios, occupational therapists and } \\
\text { everybody's going somewhere, speech therapists, ..." [Participant } 9 \text { - Nurse] }\end{array}$ \\
\hline
\end{tabular}

(Continued) 
Table I (Continued).

\begin{tabular}{|l|l|l|}
\hline Theme & \multicolumn{1}{|c|}{ Subtheme } & \multicolumn{1}{c|}{ Representative Quotation } \\
\hline $\begin{array}{l}\text { 4.4. Suggestions for the } \\
\text { future of the program }\end{array}$ & $\begin{array}{l}\text { 4.4.I Program } \\
\text { development and } \\
\text { expansion }\end{array}$ & $\begin{array}{l}\text { So I think anything group-based or group, I would say anything group-based with the } \\
\text { volunteer peers and with the patients that are more, that are dealing with depression } \\
\text { post-stroke would be beneficial, 'cause isolation is one of the hardest things for them." } \\
\text { [Participant 10 - Nurse] } \\
\text { "We have been in one way lucky that it shows the progress that they've [volunteer } \\
\text { peers] done so well in their recovery. But maybe we should have people that did not } \\
\text { recover as well because not everyone does have those improvements, but regardless } \\
\text { of that, how they are still managing and they are still coping well in their lives." } \\
\text { [Participant 2 - Allied Health Staff] }\end{array}$ \\
\hline
\end{tabular}

providing the volunteer support. Nonetheless, the nursing and allied health staff interviewed were all aware of the program. Nursing and allied health staff reported that nurses who coordinated shifts had greater involvement with volunteer peers and there was an overall staff awareness, through regularly seeing the volunteer peers on the ward, discussion at team meetings and assisting volunteer peers in locating patients and rooms.

Some nursing and allied health staff were more aware of the program through receiving queries from volunteer peers, particularly where volunteer peers sought their advice on how to handle specific situations. Nursing and allied health staff reported they liked to chat with volunteer peers after the peer visit to obtain feedback about the patient and relevant outcomes of the visit, and sometimes, volunteer peers approached ward staff for information.

Referral of patients to the SPSP and allocation of volunteer peers was undertaken as part of patient review at multidisciplinary team meetings. This was based on individual patient need and staff observations of those patients who might be lonely, anxious, depressed, or simply in need of social support. Appropriate peer-patient pairings, based on complementary levels of ability relating to mobility or cognition, were considered important.

\section{Recognising the Benefits of the Program}

From their experiences and perceptions of the program, nursing and allied health staff identified benefits for stroke patients and their family carers, as well as for volunteer peers, and nursing and allied health staff.

The SPSP was recognised as providing several benefits to patients and families. The peer visits provided social contact and experienced-based support for patients. Nursing and allied health staff observed that peer-patient interactions contributed to improving the overall well- being of patients and provided them with a sense of hope for the future. The visits also provided support to families, either through being visited by the carer-volunteer (a carer of a former stroke survivor) or through seeing the benefits of peer visits to their family member, the patient.

Nursing and allied health staff strongly emphasised the benefits of social interaction with a relatable peer who could provide experiential support. Aside from advice and support, the effect of just having some social contact was immensely helpful for enhancing patients' well-being. The differences between the care and support provided by healthcare staff versus the unique contributions which could only be provided by someone who had personally experienced a stroke was frequently emphasised by staff.

Both nursing and allied health staff spoke of the value of a shared, experience-based understanding between a peer and patient, specifically, hearing from someone who has been through it themselves. The concept of a shared experience was perceived as particularly relevant in guiding patients to realise the changes in their functional abilities may be more apparent when they returned home.

Nursing and allied health staff were aware that stroke patients can be at high risk of depression post-stroke, therefore interaction opportunities with others, not just hospital staff, were deemed important. The benefit of interacting with someone else who has been through a similar experience was noted as contributing positively to the mental health and well-being of patients. Volunteer peers provided psychosocial support that was additional to staff care and the social interactions helped alleviate patients' feelings of isolation.

Nursing and allied health staff also perceived that patients benefited from volunteer peers' ability to provide reassurance and normalisation regarding the realities of stroke rehabilitation. Nursing and allied health staff 
reiterated the overarching benefits of a shared experience between peer and patient. From their experiences of caring for stroke patients, nursing and allied health staff perceived the peer visits provided patients with a sense of hopefulness about their recovery and future which encouraged them to follow through with their rehabilitation plan.

The support from the carer-volunteer peer to the family carers of stroke inpatients was perceived as particularly helpful, as they shared the common experience of a carer role for a family member who had had a stroke and the related consequences.

Benefits to volunteer peers where also noted, as the volunteer peer support role provided a sense of purpose and giving back, plus allowed them to have social engagement and community participation. As the peer supporters were former patients of the stroke unit, they were observed enjoying chatting with staff who had cared for them in addition to sharing their experiences with patients.

In considering the wider benefits to ward staff, nursing and allied health staff felt volunteer peers provided the much-needed supplementary support to patients and families when they themselves were time poor, and this somewhat alleviated the burden of care on staff. Nursing and allied health staff perceived that peer support reduced their own mental and emotional stress incurred from the busyness and day-to-day running of the ward, allowing some relief from compassion fatigue. Nursing and allied health staff highlighted how having volunteer peers on the ward helped to reinforce and endorse key messages from healthcare staff to patients and their families.

Another benefit identified by nursing and allied health staff was that volunteer peers were able to provide insights into the support needs of the patient. Interactions between volunteer peers and patients provided a safe space where patients could articulate their needs and peers could relay vital information to staff who could then tailor a patient's individual care. A rewarding aspect for nursing and allied health staff was seeing former patients come back to the hospital site as volunteer peers.

\section{Perceived Enablers and Barriers of the Program}

Nursing and allied health staff perceived several factors which they felt contributed to or could impact upon the peer support program. Nursing and allied health staff highlighted the enablers of the program, including how program coordination and communication between ward staff and volunteer peers contributed to the success of the program. The roles of the clinical nurse and volunteer coordinator were considered fundamental.

The importance of clear communication procedures which enabled ward staff and volunteer peers to share information was also emphasised. These embedded communication procedures also facilitated keeping staff well informed and working together as a team. The enthusiasm and commitment of volunteer peers for the role and their ability to engage with patients and carers was perceived as a vital enabler which enhanced the program.

Scheduling of peer visits and patient fatigue were perceived as potential barriers of the program that should be considered. For example, due to the busyness of the stroke rehabilitation program, patients were sometimes absent from their room, or were resting in-between therapies at the pre-allocated peer visit time. In addition, volunteer peers, having been patients themselves, were very adept at recognising signs of patient tiredness and modified their visits accordingly. Nursing and allied health staff also recognised the need to support volunteer peers, as they sometimes had to manage difficult or sensitive topics raised by the patient, or deal with patients with specific needs such as aphasia.

The need for a greater pool of volunteer peers was recognised, particularly if volunteer peers were on leave, unwell or otherwise unavailable. The weekly multidisciplinary team meetings provided a forum to discuss the program. Overall, nursing, and allied health staff believed that despite logistical challenges, the overall benefits of the SPSP for patients and volunteer peers clearly outweighed any negative aspects.

\section{Suggestions for Expanding the Program}

Nursing and allied health staff recommended expanding the program to include a group support component, where groups of patients and volunteers interacted together, including activities such as outings or music therapy. Some nursing and allied health staff suggested incorporating interactions between ward staff and volunteer peers through social activities, such as a regular afternoon tea, as a way of building staff-volunteer peer relationships. To maximise the program's benefits, nursing and allied health staff suggested the need to review logistical aspects of the program, including the matching of volunteers to patients. Others recommended reconsidering the timing of visits to occur across the day rather than a limited window of time in the early afternoon. 
Furthermore, a more diverse volunteer peer pool was suggested as part of future program expansion, as some nursing and allied health staff felt a wider variety of volunteer peers would increase stroke patients' and carers' awareness of the variability of recovery and disability between individual stroke survivors. This idea was further particularised, for example, seeking and recruiting volunteer peers with physical mobility and language challenges.

As only one carer-volunteer peer was part of the program, nursing and allied health staff also recommended acquiring more peers of this type, to better support family carers of recent stroke survivors. Nursing and allied health staff recognised the importance of an appropriate environment for the peer visits so conversations could be private, which is a challenge in dual-bed patient rooms and suggested creating a dedicated peer visit space. Additionally, nursing, and allied health staff believed the whole ward team approach to the program was crucial.

\section{Discussion}

The findings of this study provide insight into nursing and allied health staff perspectives of providing volunteer peer support for stroke patients. All nursing and allied health staff were aware of the program and of the roles of multidisciplinary staff in the development of the program (recruitment and training of volunteer peers and program design), as well as the factors which allowed for successful delivery of the program (referral of eligible patients, suggesting appropriate peer-patient pairings, supporting volunteer peers and effective program coordination). Nursing and allied health staff emphasised how the whole ward team approach enhanced the program's success.

These combined factors highlight the need for leadership of volunteer peer support programs, and due to close and frequent patient care interactions and skillsets, nurses are ideally positioned to lead such programs. Evaluation of nurse-led volunteer programs have found nurses have the skills, knowledge, and experience to develop programs and support volunteers. ${ }^{16}$

The findings showed that volunteer peers interacted with ward staff and were comfortable in seeking their advice. The engagement with ward staff and the positive relationships between staff and volunteer peers no doubt contributed to the positive perceptions of nursing and allied health staff. Other studies have also found staff engagement was critical to the success of stroke peer support programs. ${ }^{10,11}$ Nursing and allied health staff observed volunteer peers were able to provide social and emotional support to stroke patients. This aligns with other findings where peer support in healthcare was repeatedly associated with emotional, informational, and appraisal support. $^{11,17,18}$

Another key finding was the recognition of peer-patient relationships as uniquely beneficial, based upon shared experiences and a common bond between current stroke patients and former stroke survivors. Ketokivi ${ }^{19}$ examined peer support in the context of various health conditions and other challenging life stressors, such as the loss of a spouse, and found peer support provided unique benefits in terms of a "social bond", shared experience, and a sense of social validation for the recipient. Further to this, Morris and Morris $^{20}$ evaluated an in-hospital, group-based peer support program and found peer-patient dyads with the greatest similarity were perceived by patients to be the most valuable in terms of support. These findings highlight the importance of appropriate and well considered pairings of stroke patients and volunteer peers. Further to this, in our study, some nursing and allied health staff noted mismatches between patients and peers, leading to stroke patients not fully engaging during the peer visit, and suggested this issue needs consideration when further refining and developing the program.

A common challenge for stroke patients is the potential for social isolation and difficulty in reintegration into the community after discharge. Salter, Hellings, Foley, and Tease $l^{21}$ found that stroke survivors who engage in volunteering benefit from meaningful social participation and improved confidence, greater self-esteem, and enhanced mood. Similarly, nursing, and allied health staff in this study identified the benefits to volunteer peers, which included keeping them socially engaged, active, and providing them with purpose and community reintegration, all of which highlight the reciprocal benefits of volunteer peer support.

\section{Limitations}

This study was limited by a sample of nursing and allied health staff from a single hospital which provides a volunteer peer support program for stroke patients. As such, the transferability of findings needs to be considered and may not be generalisable to other programs. Despite the limitations of the sample, the study provides an exploration of the perspectives of nursing and allied health staff caring for stroke patients and interacting with volunteer peers. As nursing and allied health staff self-selected for 
involvement in interviews, an inherent bias may exist, as participating nursing and allied health staff may have had more interest in the volunteer program. However, findings indicate nursing and allied health staff provided positive perspectives along with constructive critiques and suggestions for improvement. Despite these limitations, the findings add to the body of knowledge regarding the benefits of volunteer peer support programs for stroke patients, family carers, volunteer peers and staff.

\section{Conclusion}

From the experiences of nursing and allied health staff at a public metropolitan hospital, the SPSP was perceived to be a valuable adjunct to hospital-based rehabilitation of stroke patients, and this outcome has informed the decision to continue the program. Volunteer peer support provided by former stroke survivors, or family carers of, can provide uniquely valuable psychosocial, informational, and experiential support to stroke inpatients and their family carers, to facilitate psychological adaptation to stroke. Volunteer peer support programs can benefit staff of specialist stroke teams by providing needed non-clinical support which may alleviate nursing care burden. The volunteer peer role allows former stroke survivors, or family carers of, to remain active and engage in meaningful, altruistic interactions which can foster their own ongoing rehabilitation.

\section{Disclosure}

The authors report no conflicts of interest in this work.

\section{References}

1. Johnson CO, Nguyen M, Roth GA, et al. Global, regional, and national burden of stroke, 1990-2016: a systematic analysis for the Global Burden of Disease Study 2016. Lancet Neurol. 2019;18(5):439-458. doi:10.1016/S1474-4422(19)30034-1

2. World Stroke Organization. Global stroke fact sheet; 2019. Available from: https://www.world-stroke.org/publications-and-resources/ resources/global-stroke-fact-sheet. Accessed December 17, 2021.

3. Adams AG, Henry JD, Molenberghs P, Robinson GA, Nott Z, von Hippel W. The relationship between social cognitive difficulties in the acute stages of stroke and later functional outcomes. Soc Neurosci. 2020;15(2):158-169. doi:10.1080/17470919.2019.1668845

4. McCurley JL, Funes CJ, Zale EL, et al. Preventing chronic emotional distress in stroke survivors and their informal caregivers. Neurocrit Care. 2019;30(3):581-589. doi:10.1007/s12028-018-0641-6
5. White CL, Barrientos R, Dunn K. Dimensions of uncertainty after stroke: perspectives of the stroke survivor and family caregiver. $J$ Neurosci Nurs. 2014;46(4):233-240. doi:10.1097/jnn.00000000000 00066

6. Harrison M, Ryan T, Gardiner C, Jones A. Psychological and emotional needs, assessment, and support post-stroke: a multi-perspective qualitative study. Top Stroke Rehabil. 2017;24(2):119-125. doi:10. 1080/10749357.2016.1196908

7. National Stroke Foundation. Clinical guidelines for stroke management; 2010. Available from: https://www.pedro.org.au/wp-content/ uploads/CPG_stroke.pdf. Accessed December 17, 2021.

8. National Institute for Health and Care Excellence. Stroke rehabilitation in adults: clinical guidelines; 2013. Available from: https://www. nice.org.uk/guidance/cg162/resources/stroke-rehabilitation-in-adultspdf-35109688408261. Accessed December 17, 2021.

9. Australian Institute of Health and Welfare. Stroke and its management in Australia: an update (Cardiovascular disease series no. 37. Cat. no. CVD 61); 2013. Available from: https://www.aihw.gov.au/ getmedia/3d56c949-68a4-46f3-bc7c-c40c89904d38/13994.pdf.aspx? inline=true. Accessed December 17, 2021.

10. National Stroke Foundation. National Stroke Foundation Hospital Peer Support Program: A Report on the Hospital Peer Support Program Pilot 2008. Melbourne, Australia: National Stroke Foundation; 2008.

11. Kessler D, Egan M, Kubina L-A. Peer support for stroke survivors: a case study. BMC Health Serv Res. 2014;14(1):1-9. doi:10.1186/14726963-14-256

12. Nelson ML, Thombs R, Yi J. Volunteers as members of the stroke rehabilitation team: a qualitative case study. BMJ Open. 2020;10(4): e032473. doi:10.1136/bmjopen-2019-032473

13. Goehner A, Kricheldorff C, Bitzer EM. Trained volunteers to support chronically ill, multimorbid elderly between hospital and domesticity: a systematic review of one-on-one-intervention types, effects, and underlying training concepts. BMC Geriatr. 2019;19(1):1-21. doi:10.1186/s12877-019-1130-2

14. Braun V, Clarke V. Using thematic analysis in psychology. Qual Res Psychol. 2006;3(2):77-101. doi:10.1191/1478088706qp063oa

15. Lincoln YS, Guba EG. Naturalistic Inquiry. California, USA: Sage Publications; 1985.

16. Charalambous L. A nurse-led youth volunteering project to support older people on acute hospital wards. Nurs Manage. 2021;28(3). doi:10.7748/nm.2020.e1926

17. Ch'Ng AM, French D, Mclean N. Coping with the challenges of recovery from stroke: long term perspectives of stroke support group members. J Health Psychol. 2008;13(8):1136-1146. doi:10.1177/ 1359105308095967

18. Dennis C-L. Peer support within a health care context: a concept analysis. Int J Nurs Stud. 2003;40(3):321-332. doi:10.1016/s00207489(02)00092-5

19. Ketokivi K. Sharing the same fate: the social bond between the self and fellow sufferers in the context of peer support. Eur Soc. 2009;11 (3):391-410. doi:10.1080/14616690902764815

20. Morris R, Morris P. Participants' experiences of hospital-based peer support groups for stroke patients and carers. Disabil Rehabil. 2012;34(4):347-354. doi:10.3109/09638288.2011.607215

21. Salter K, Hellings C, Foley N, Teasell R. The experience of living with stroke: a qualitative meta-synthesis. J Rehabil Med. 2008;40 (8):595-602. doi:10.2340/16501977-0238 


\section{Publish your work in this journal}

The Journal of Multidisciplinary Healthcare is an international, peerreviewed open-access journal that aims to represent and publish research in healthcare areas delivered by practitioners of different disciplines. This includes studies and reviews conducted by multidisciplinary teams as well as research which evaluates the results or conduct of such teams or healthcare processes in general. The journal

covers a very wide range of areas and welcomes submissions from practitioners at all levels, from all over the world. The manuscript management system is completely online and includes a very quick and fair peer-review system. Visit http://www.dovepress.com/testimonials. php to read real quotes from published authors. 